\title{
Vitamin D and inflammation in the prevention of type 2 diabetes: public health relevance
}

Alaa Badawi ${ }^{1}$, Eman Sadoun ${ }^{2}$, Mohamed H. Al Thani ${ }^{2}$

1 Office for Biotechnology, Genomics and Population Health, Public Health Agency of Canada, Toronto, ON, Canada

2 Supreme Council of Health, Doha, Qatar

\section{Abstract}

The incidence of type 2 diabetes mellitus (T2DM) is increasing worldwide. To reduce the disease risk and burden at the population level, preventative strategies should be developed with minimal cost and effort and with no side-effects. Low-grade inflammation resulting from imbalances in the innate immune system has been associated with an array of chronic disorders that predispose to the later development of T2DM (e.g., obesity, metabolic syndrome, and insulin resistance). As a result, inflammation may contribute to the pathogenesis of T2DM. Therefore, attenuation of this inflammatory response via modulating the innate immune system could lead to improved insulin sensitivity and delayed disease onset. Dietary supplementation with vitamin D may represent a novel strategy toward the prevention and control of T2DM at the population level due to its antiinflammatory and antioxidant properties. This review examines current knowledge linking T2DM to chronic low-grade inflammation and the role of vitamin $\mathrm{D}$ in modulating this relationship. The concept that vitamin $\mathrm{D}$, via attenuating inflammation, could be employed as a novel preventive measure for T2DM is evaluated in the context of its relevance to health care and public health practices.

\section{Keywords}

Inflammation; Prevention; Public health; Type 2 diabetes; Vitamin D 


\section{Introduction}

Type 2 diabetes mellitus (T2DM) represents a significant global health problem. It is estimated that about six people die every minute from the disease worldwide, a figure that will soon make T2DM one of the world's most prevalent health problems [1]. T2DM is associated with increased morbidity (blindness, renal failure, amputation) and mortality, and it is a risk factor for cardiovascular disease (CVD) and stroke. T2DM depletes significant proportion of the healthcare system resources both in the developed and developing countries, an issue that is expected to further exacerbate over the next two decades [2]. Risk factors for T2DM include age $\geq 40$ years, obesity, ethnicity, genetics, diet and physical activity [3]. Drug therapy and lifestyle interventions such as weight loss, diet and exercise are traditional strategies for prevention and treatment of T2DM. However, adherence to lifestyle changes is difficult for many individuals, and the high cost of treatment poses a large financial burden on the health care system. Therefore, there is a need to develop novel approaches for interventions that can be implemented at the population level and targeted towards "at-risk" sub-populations, with maximum efficacy and minimal financial cost.

T2DM is a progressive chronic disease characterized by insulin resistance and $\beta$-cell dysfunction. Insulin resistance is defined as the inability of skeletal muscle, liver and adipose tissue to respond adequately to the body's endogenous insulin secretions. In addition to insulin resistance, $\beta$-cell dysfunction plays an integral role in the pathogenesis of T2DM. In healthy individuals, the $\beta$-cells are able to counteract insulin resistance by increasing insulin production and secretion [4]. Glucose sensors located on $\beta$-cells sense increases in blood glucose levels despite increases in insulin secretion; this persistent hyperglycemia triggers a series of events which ultimately leads to an increase in $\beta$-cell expression, $\beta$-cell mass and enhanced secretory capacity of the pancreas. However, in individuals with T2DM this increase in $\beta$-cell mass and secretory capacity is disrupted [5].

There is growing evidence that abnormal innate immune responses and chronic low-grade inflammation play a key role in the pathogenesis of insulin resistance and T2DM [6-10]. Inflammation results from the activation of the innate immune response: the body's immediate, non-specific reaction against environmental insults such as pathogens, chemical or physical injury. Inflammation plays a role in tissue damage prevention, restoration of tissue homeostasis and destruction of infectious agents [11]. It is the result of a system-wide process known as the "acute-phase response". During the acute-phase response, an array of pro-inflammatory cytokines, such as tumor necrosis factor (TNF)- $\alpha$, interleukin (IL)- $1 \beta$ and IL-6, are released, primarily by macrophages [12] to enhance insulin resistance directly in adipocytes, muscle and hepatic cells [10], resulting in disruption of insulin homeostasis and impaired glucose tolerance [13]. Increased levels of pro-inflammatory cytokines lead to hepatic production and secretion of acute-phase proteins such as C-reactive protein (CRP), plasminogen activator inhibitor-1 (PAI-1), serum amyloid-A, $\alpha_{1}$-acid glycoprotein, fibrinogen, and haptoglobin. These proteins, collectively known as inflammatory markers, appear in the metabolic syndrome and early stages of T2DM, and their circulating levels increase as the disease progresses [14]. Indeed, many studies have documented a relationship between these inflammatory markers and T2DM (for review, see [15]).

Nutritional interventions aimed at reducing systemic inflammation could lead to improved insulin sensitivity and delayed disease onset. Adequate physiologic status of anti-inflammatory nutrients has been associated with reduced levels of pro-inflammatory cytokines and risk of T2DM [15]. In particular, vitamin D may improve insulin sensitivity and promote $\beta$-cell survival by down-regulating the generation and effects of pro-inflammatory cytokines $[15,16]$. In this respect, epidemiological studies suggest that adequate vitamin D status may help prevent the development of T2DM, whereas vitamin $\mathrm{D}$ deficiency can be associated with T2DM risk [17]. Supplementation with vitamin D may, therefore, have a significant public health potential in the general population, particularly in sub-populations known to have a high prevalence of vitamin D deficiency. By attenuating inflammation, vitamin D 
may improve insulin resistance and subsequently prevent or delay the onset of T2DM. The concept has been reported, for example, when the modifying effect of vitamin $\mathrm{D}$ was examined on the associations between T2DM and variants of the peroxisome proliferator-activated receptor $\delta(P P A R \delta)$, a gene known to predispose to diabetes risk [18]. Elucidating the association between inflammatory markers and early stages of T2DM, on the one hand, and the role of vitamin D on modifying this relationship, on the other hand, may allow evaluating the use of inflammatory networks in early disease risk prediction. Understanding this interrelationship may also facilitate the characterization of biomarkers (e.g., genome-based, proteomics or metabolomics) associated with vitamin D intake.

The present article was undertaken in an attempt to evaluate the relationship between vitamin $\mathrm{D}$, inflammation and the risk of T2DM and how to employ this association in developing public health approaches for disease early risk prediction and prevention.

\section{Vitamin D metabolism, synthesis, and serum levels}

Humans obtain vitamin $\mathrm{D}$ through the production of cholecalciferol (vitamin $\mathrm{D}_{3}$ ) in the epidermis after ultraviolet irradiation of 7-dehydrocholesterol, and by the absorption of cholecalciferol or its plant equivalent (ergocalciferol) from the intestine after intake of vitamin D-rich foods [19]. Cholecalciferol is hydroxylated in the liver by the 25-hydroxylase (CYP2R1) to $25(\mathrm{OH}) \mathrm{D}$, which is the major circulating form of vitamin D [19]. In the kidney, 1a-hydroxylase (CYP27B1) then hydroxylates 25(OH)D to $1 \alpha, 25(\mathrm{OH})_{2} \mathrm{D}$, that is considered a steroid hormone. This active form of the vitamin, via binding to vitamin $\mathrm{D}$ receptor (VDR), influences the transcriptional regulation of an array of genes and activates numerous signal transduction pathways [19]. Moreover, the $1 \alpha, 25(\mathrm{OH})_{2} \mathrm{D}$ maintains calcium homeostasis by increasing calcium absorption by the intestinal mucosa, decreasing calcium excretion by the kidney, and promoting bone resorption via parathyroid hormone (PTH) when serum calcium falls to suboptimal levels [20].

Reduced sun exposure, either due to living in latitudes with seasonal shortages of UV radiation (e.g., in the Northern hemisphere) or due to extensive body coverage by clothes (e.g., in many countries of the Middle East), often translates into difficulties maintaining an adequate vitamin D status and a need to obtain this micronutrient orally, e.g., via supplementation [21]. The elderly, certain ethnocultural groups, and individuals with malabsorption diseases are at risk of becoming vitamin D deficient [22,23]. In addition, recent genome-wide association studies suggest that common genetic variations, e.g, in CYP2R1, may also affect vitamin D status [24-26]. Dietary factors such as fish liver oil, fatty fish, including sardines and salmon, egg yolks and fortified milk are important nutritional sources of vitamin D [27]. Until very recently, the accepted adequate intake (AI) of vitamin D, which maintains serum levels preventing osteomalacia and rickets and based on the absence of sufficient exposure to sunlight, was $5 \mu \mathrm{g} /$ day (200 IU) (as cholecalciferol) for adults, $10 \mu \mathrm{g} / \mathrm{day}$ (400 IU) for people aged 51-70 years, and $15 \mu \mathrm{g} /$ day (600 IU) for those aged 71 years and older [28,29]. The tolerable upper intake level (UL) was set at $50 \mu \mathrm{g} /$ day (2000 IU), based on preventing the development of hypercalcemia. However, very recently the Institute of Medicine (IOM) of the US National Academy of Sciences has released new daily recommended intakes for vitamin $\mathrm{D}$ that reflect an increased understanding of the role of vitamin $\mathrm{D}$ in a number of physiological processes aside from bone metabolism. The new recommended dietary allowance (RDA) for individuals younger than 71 years is $600 \mathrm{IU} /$ day, with an increased RDA of $800 \mathrm{IU} /$ day for those who are 71 or older. Furthermore, the UL has been doubled to a maximum of $4,000 \mathrm{IU} /$ day for adults [30]. The primary concern with consuming a greater amount of vitamin D is the potential vitamin $\mathrm{D}$ toxicity. However, the amount of vitamin $\mathrm{D}$ required to produce toxic effects (in individuals with no vitamin $\mathrm{D}$ hypersensitivity) was suggested to be equivalent to chronically consuming 40,000 IU/day [31]. 
Vitamin D status is assessed by measuring 25(OH)D and serum levels $>50 \mathrm{nmol} / \mathrm{l}(>20 \mathrm{ng} / \mathrm{ml})$ traditionally have been considered adequate, although increasing evidence strongly suggests that concentrations $>75 \mathrm{nmol} / \mathrm{l}(>30 \mathrm{ng} / \mathrm{ml})$ are necessary for optimal health $[9,28,32]$. Vitamin D deficiency is defined as serum levels of $25(\mathrm{OH}) \mathrm{D}<27.5 \mathrm{nmol} / \mathrm{l}$ [33], whereas concentrations $>375 \mathrm{nmol} / \mathrm{l}$ are thought to be toxic [27]. Prevalence of vitamin D deficiency may be higher among subjects of non-Caucasian origin [33], due to a decreased rate of ultraviolet radiation absorption by dark skin that results in diminished vitamin D production [34]. Indeed, we have shown recently that the average serum $25(\mathrm{OH}) \mathrm{D}$ concentration in individuals with dark skin color (East Asians and South Asians) is 1.5-fold lower than that in Caucasians [23].

\section{Vitamin $\mathrm{D}$, inflammation, and T2DM}

Vitamin D homeostasis has been linked to conditions such as neuromuscular function, cancer, autoimmune diseases, atherosclerosis, CVD, and diabetes. A number of prospective studies have demonstrated an association between high level of inflammation and the development of T2DM [15].

The identification of the vitamin D responsive element (VDRE) in the insulin receptor gene promoter (INSR) suggests that $1 \alpha, 25(\mathrm{OH})_{2} \mathrm{D}$ may influence insulin sensitivity via the transcriptional up-regulation of the INSR [35]. The CYP27B1, which hydroxylates $25(\mathrm{OH}) \mathrm{D}$ into $1 \alpha, 25(\mathrm{OH})_{2} \mathrm{D}$, was originally thought to be present only in renal tissue. However, more recently CYP27B1 was identified in extrarenal tissues including pancreatic $\beta$-cells, which suggests that it may be required for their function [36]. The presence of VDRs and vitamin D binding protein (VDBP) in pancreatic $\beta$-cells has initiated studies demonstrating a relationship between single nucleotide polymorphisms (SNPs) in the genes regulating VDR, VDBP and glucose intolerance, and insulin secretion [37-39]. The $1 \alpha, 25(\mathrm{OH})_{2} \mathrm{D}$ may be required for insulin synthesis [40] and may influence its secretion by increasing the expression of calbindin$\mathrm{D} 28 \mathrm{~K}$ in $\beta$-cells [41]. Calbindin-D28K has an integral role in regulating intracellular calcium levels of $\beta$-cells, thus facilitating insulin exocytosis, a calcium-dependent process [41].

In addition to its actions on $\beta$-cell function, vitamin D may play a role in T2DM through its potent immunomodulatory functions [42-44]. As reviewed recently by our group [15,16], one of the hallmarks of T2DM is systemic low-grade inflammation, which is characterized by increased serum levels of proinflammatory cytokines and acute phase reactants. In vitro, $1 \alpha, 25(\mathrm{OH})_{2} \mathrm{D}$ protects human islets that are incubated with pro-inflammatory cytokines from apoptosis [45] and modulates the production of the immunostimulatory cytokine IL-12 and the immunosuppressive cytokine IL-10 [46]. Furthermore, VDRs are present in most types of immune cells, thus suggesting a role of vitamin D in the immunity [47]. Additionally, vitamin D supplementation has been shown to reduce inflammatory cytokines such as IL-6 and TNF- $\alpha$, which play a critical role in mediating insulin resistance [48]. These effects of vitamin $\mathrm{D}$ on cytokines and cytokine synthesis is due to its interaction with VDREs in the promoter region of cytokine-encoding genes that downregulates the transcriptional activities of cytokine genes and attenuates the synthesis of the corresponding proteins [49]. Vitamin D also deactivates the nuclear receptor kappa $\mathrm{B}(\mathrm{NF \kappa B})$, which transcriptionally regulates the pro-inflammatory cytokine genes [50]. Downregulating the NFKB, and the downstream cytokine genes, it promotes $\beta$-cell survival and improves insulin secretion [49].

Vitamin D deficiency has been linked to T2DM, because circulating levels of 25(OH)D were lower in patients than in controls $[51,52]$. In normoglycemic subjects, $25(\mathrm{OH}) \mathrm{D}$ was inversely associated with post-prandial plasma glucose, fasting insulin and insulin resistance (defined as homeostatic model assessment of insulin resistance - HOMA-IR) [53]. Data from the Third National Health and Nutrition Examination Survey (NHANES III) showed that serum 25(OH)D was inversely associated with T2DM and HOMA-IR [54]. We have also reported an inverse association between vitamin D serum 
levels and HOMA-IR in a population of non-diabetic adults [23]. This inverse association suggests that $25(\mathrm{OH}) \mathrm{D}$ may play a role in decreasing insulin resistance upon sufficiency. A more recent crosssectional study conducted in non-diabetic individuals noted an inverse association between plasma 25(OH)D and fasting plasma glucose, insulin concentration and HOMA-IR and a positive association with the insulin sensitivity index (ISI). In this study, separating subjects into tertiles based on their serum $25(\mathrm{OH}) \mathrm{D}$ concentration showed that those in the highest tertile $(64 \mathrm{nmol} / \mathrm{l})$ had significantly lower fasting plasma glucose, fasting plasma insulin and insulin resistance than those in the lowest tertile (30 nmol/l) [55]. Indeed, this inverse relationship between vitamin D serum levels and the risk of T2DM has been recently addressed from the perspective of the role of this micronutrient (and others) in disease intervention [56]. To further substantiate the role of vitamin D in T2DM risk, we have also reported that increasing plasma vitamin $\mathrm{D}$ level by $10 \mathrm{nmol} / \mathrm{l}$ can reduce predisposition to T2DM by $14 \%$ in a population of healthy adults [23]. Moreover, a higher prevalence of severe vitamin D deficiency $(<14 \mathrm{nmol} / \mathrm{l})$ was also observed among diabetic women than healthy controls $(39 \%$ in T2DM vs. $25 \%$ in controls) [52]. A study assessing joint vitamin D and calcium intake showed that individuals with vitamin D (> $800 \mathrm{IU} /$ day) and calcium (> $1200 \mathrm{mg} /$ day) intake had a 33\% lower risk of T2DM vs. those who had a vitamin D at $<400 \mathrm{IU} /$ day and calcium at $<600 \mathrm{mg} / \mathrm{d}$ [57]. Three years of calcium and vitamin D supplementation improved fasting glucose in those with impaired glycemia and resulted in a smaller increase in insulin resistance (HOMA-IR) vs. the placebo group [42].

\section{Genetic variation, vitamin D status, and inflammatory biomarkers}

As mentioned above, there is evidence in favor of a relationship between vitamin D status and predisposition to T2DM, which may be a result of the immunomodulatory and anti-inflammatory properties of vitamin D. However, the association remains inconsistent and this may reflect confounding factors, such as genetic variation affecting the individual responses to vitamin $\mathrm{D}$. The role of common genetic variants on vitamin D status has recently begun to be elucidated [24-26]. A meta-analysis of genome wide association studies (GWAS) combined results from $~ 4,500$ individuals of European ancestry and found significant associations between 25(OH)D concentrations and SNPs in the following genetic loci: $G C$ (the gene coding for VDBP), NADSYN1 (encoding nicotinamide adenine dinucleotide synthetase), which is in high linkage disequilibrium with a SNP in DHCR7 (encoding 7-dehydrocholesterol reductase, which synthesizes cholesterol from 7-dehydrocholesterol), and CYP2R1 (encoding cytochrome P450, family 2, subfamily R, polypeptide 1, a C-25 hydroxylase that converts cholecalciferol to $\left.1 \alpha, 25(\mathrm{OH})_{2} \mathrm{D}\right)$ [26]. Similar results were obtained in another meta-analysis of GWAS studies, which evaluated serum levels of $25(\mathrm{OH}) \mathrm{D}$ and genetic variation in a pooled sample of cohorts consisting of $\sim 34,000$ individuals of European origin [25]. A recent candidate gene study examined the relationship between common genetic variants of $G C$ and the response of serum levels of $25(\mathrm{OH}) \mathrm{D}$ to vitamin D supplementation [24]. This group found that a common functional variant of this gene, T436K (rs4588, c.1307C > A) predicted differences in response of 25(OH)D levels to supplementation. These studies indicate that genetic variants in loci involved in cholesterol synthesis, hydroxylation and vitamin D transport may play a role in determining vitamin D status. Furthermore, we have shown recently that SNPs in the innate immunity-related inflammatory pathway influence the risk of T2DM and that this effect can be mitigated by vitamin D [58]. Although traditional technologies allowed for examining the associations between one or a few biomarkers and specific outcomes of interest, current advances in proteomics and metabolomics have made it possible to simultaneously determine the circulating concentrations of multiple proteins and metabolites, respectively. Apparently, therefore, genes along the vitamin D metabolic pathway and action and those along the innate immunity-related 
inflammation can interact to influence the preventive efficacy of vitamin D on T2DM. Employing such a multiplexed approach in relation to vitamin $\mathrm{D}$ and inflammation would allow for assessing its effects on multiple biomarkers simultaneously. This assessment may also permit to develop an "omics"-based signature to distinguish responders to vitamin $\mathrm{D}$ intake from non-responders to whom alternative preventive measures can be introduced.

\section{Vitamin D in the prevention of T2DM: clinical trials}

To date, few clinical trials have assessed the effects of vitamin D supplementation on glycemia, insulin resistance, and the progression and complications of T2DM have yielded inconsistent results. In one study, diabetic women supplemented with $1332 \mathrm{IU} / \mathrm{d}$ for one month increased first phase insulin secretion (FPIS) and second phase insulin secretion (SPIS) by $34 \%$ and $20 \%$, respectively [59]. FPIS plays an integral role in reducing post-prandial glucose levels [59]. These findings suggest that vitamin D deficiency may decrease insulin secretion and that supplementation may help restore insulin secretion, thus ameliorating T2DM. We summarized a number of observational longitudinal cohort studies and randomized controlled trials evaluating the effect of vitamin D on diabetes and its related risk factors in Table I.

A randomized, placebo-controlled study examined the effect of vitamin D (400 IU/day) and calcium $(1000 \mathrm{mg} /$ day $)(\mathrm{Ca}+\mathrm{D})$ on the risk of T2DM in non-diabetic, postmenopausal women [60]. At the 7-year follow-up, there were 2291 newly diagnosed cases of T2DM; however, no difference between the $\mathrm{Ca}+\mathrm{D}$ and placebo groups was observed (Table I). Although this study did not show a significant negative association between $\mathrm{Ca}+\mathrm{D}$ and developing $\mathrm{T} 2 \mathrm{DM}$, it is important to note that the amount of vitamin D given was low compared to that used in previous studies ( $\geq 2000 \mathrm{IU} /$ day) [42]. More recently, a randomized placebo-controlled trial conducted by von Hurst et al. examined the effect of vitamin D (4000 IU/day) on insulin sensitivity and secretion in a cohort of insulin resistant, vitamin $\mathrm{D}$ deficient women [62]. After six months of vitamin D supplementation, serum 25(OH)D increased from 21 to $75 \mathrm{nmol} / \mathrm{l}$. Significant improvements in insulin sensitivity and a decrease in fasting glucose and insulin resistance were also observed in the treated group vs. placebo [62]. However, this study only included women, and the measure of insulin sensitivity used was HOMA, which is calculated from fasting glucose and insulin. HOMA is used widely in epidemiological studies because it is cheap and easy to obtain; however, it is a measure of liver insulin sensitivity rather than of muscle or whole body insulin sensitivity. The study showed that vitamin D supplementation had no effect on fasting serum glucose (Table I). This is important because, clinically, diabetes and other forms of dysglycemia are identified by measuring fasting and/or post-prandial blood glucose. Thus, it is important to know whether vitamin $\mathrm{D}$ can influence fasting or post-prandial blood glucose. To date, very few clinical trials have been conducted to examine this question and have analyzed the effects of physiological dosages (50-4000 IU/day) on markers of T2DM. However, few have examined the effects of administering supra-physiological doses of vitamin D. One study conducted in healthy, centrally-obese, non-diabetic men examined the effect of three oral doses of 120,000 IU of vitamin D or placebo over a period of six weeks on HOMA-IR, insulin sensitivity, OGIS and insulin secretion [63] (Table I). The study found that supplementation improved OGIS compared to placebo although this effect was on the board of being significant [63]. However, no changes were observed in the other outcome measures despite the increase in serum $25(\mathrm{OH}) \mathrm{D}$. The data in Table I permitted us to conclude that vitamin D serum levels of more than $30 \mathrm{ng} / \mathrm{ml}$ (> $73.8 \mathrm{nmol} / \mathrm{l}$, i.e., the recent cut-off for vitamin D sufficiency of $75 \mathrm{nmol} / \mathrm{l}$ ) can, indeed, be associated with significant improvement in a number of metabolic phenotypes related to T2DM. This observation suggests that a public health strategy based on increasing serum levels of vitamin D may provide an effective approach for T2DM intervention in the general population. This 


\begin{tabular}{|c|c|c|c|c|c|c|}
\hline Gender & $n^{2}$ & $\begin{array}{l}\text { Age at } \\
\text { baseline } \\
\text { (mean) }\end{array}$ & $\begin{array}{c}\text { Vitamin D } \\
\text { (intake/serum level }{ }^{3} \text { or } \\
\text { supplementation) }\end{array}$ & $\begin{array}{l}\text { Duration } \\
\text { of follow-up or } \\
\text { treatment }(y r s)^{9}\end{array}$ & $\begin{array}{c}\text { RR, OR, or HR } \\
\left(95 \% \mathrm{Cl}, \mathrm{p}_{\text {trend }}\right) \text { or } \\
\text { improved outcome }(p)^{10}\end{array}$ & Ref. \\
\hline \multicolumn{7}{|c|}{ Observational longitudinal cohort studies } \\
\hline \multirow[t]{3}{*}{ M } & 1628 & 57 & Level: 30 vs. $10 \mathrm{ng} / \mathrm{ml}$ & 22 & $0.49(0.15-1.64 ; 0.06)$ & [64] \\
\hline & 1948 & 53 & Level: 31 vs. 9 ng/ml & 17 & $0.17(0.05-0.52 ;<0.001)$ & [64] \\
\hline & 25,877 & 57 & Intake: 720 vs 188 IU/d & 5 & $0.96(0.74-1.23 ; 0.35)$ & [65] \\
\hline \multirow[t]{6}{*}{$\mathrm{F}$} & 10,066 & 52 & Intake: > 511 vs. $<159$ IU/d & 9 & $0.73(0.54-0.99 ; 0.02)$ & [66] \\
\hline & 83,779 & 46 & Intake: > 800 vs. $<200$ IU/d & 20 & $0.87(0.69-1.09 ; 0.67)$ & [57] \\
\hline & 1699 & 57 & Level: 25 vs. 9 ng/ml & 22 & $0.91(0.37-2.23 ; 0.66)$ & [64] \\
\hline & 2228 & 55 & Level: 25 vs. $8 \mathrm{ng} / \mathrm{ml}$ & 17 & $1.45(0.58-3.62 ; 0.83)$ & [64] \\
\hline & 33,919 & 57 & Intake: 696 vs. 192 IU/d & 5 & $0.88(0.67-1.16 ; 0.67)$ & [65] \\
\hline & 32,826 & 46 & Level: 33 vs. 14 ng/ml & 14 & $0.52(0.33-0.83 ; 0.008)$ & [67] \\
\hline$M: F=1: 0.8$ & 2956 & 60 & Level: 22 vs. $17 \mathrm{ng} / \mathrm{ml}$ & 7 & $0.60(0.37-0.97 ; 0.03)$ & [68] \\
\hline \multicolumn{7}{|c|}{ Randomized controlled trials } \\
\hline M & 71 & 43 & $\mathrm{D}_{3}: 8571 \mathrm{IU} / \mathrm{d}^{4}$ & 6 (wks) & $\begin{array}{l}\text { OGIS (0.055) } \\
\text { HOMA-IR (0.95) }\end{array}$ & [61] \\
\hline \multirow[t]{5}{*}{$\mathrm{F}$} & 151 & 49 & $\begin{array}{l}\mathrm{D}_{3}: 2000 \mathrm{IU} / \mathrm{d}\left(\mathrm{Ca}^{++} 500 \mathrm{mg} / \mathrm{d}\right) \\
1(\mathrm{OH}) \mathrm{D}_{3}: 0.25 \mathrm{mcg} / \mathrm{d}\left(+\mathrm{Ca}^{++}\right)\end{array}$ & 2 & FPG $(0.97)$ & [69] \\
\hline & 33,951 & 62 & $\mathrm{D}_{3}: 400 \mathrm{IU} / \mathrm{d}\left(\mathrm{Ca}^{++} 1000 \mathrm{mg} / \mathrm{d}\right)$ & 7 & HR (0.95) & [60] \\
\hline & 1637 & 65 & $\mathrm{D}_{3}: 400 \mathrm{IU} / \mathrm{d}\left(\mathrm{Ca}^{++} 1000 \mathrm{mg} / \mathrm{d}\right)$ & 6 & FPG (0.32) & [60] \\
\hline & 1457 & 65 & $\mathrm{D}_{3}: 400 \mathrm{IU} / \mathrm{d}\left(\mathrm{Ca}^{++} 1000 \mathrm{mg} / \mathrm{d}\right)$ & 6 & FPG (0.79) & [60] \\
\hline & 81 & 42 & $\mathrm{D}_{3}: 4000 \mathrm{IU} / \mathrm{d}$ & 0.5 & $\begin{array}{l}\text { FPG (0.82) } \\
\text { HOMA-IR (0.02) }\end{array}$ & [62] \\
\hline$M: F=1: 1.6$ & 222 & 71 & $\mathrm{D}_{3}: 700 \mathrm{IU} / \mathrm{d}\left(\mathrm{Ca}^{++} 500 \mathrm{mg} / \mathrm{d}\right)$ & 3 & FPG (0.55) & [42] \\
\hline$M: F=\sim 1: 1$ & 92 & 71 & $\mathrm{D}_{3}: 700 \mathrm{IU} / \mathrm{d}\left(\mathrm{Ca}^{++} 500 \mathrm{mg} / \mathrm{d}\right)$ & 3 & FPG $(0.042)$ & [42] \\
\hline$M: F=\sim 1: 1$ & 34 & 64 & $\mathrm{D}_{3}: 1785 \mathrm{IU} / \mathrm{d}\left(\mathrm{Ca}^{++} 500 \mathrm{mg} / \mathrm{d}\right)^{5}$ & 8 (wks) & $\begin{array}{l}\text { HbA1c }(0.74) \\
\text { HOMA-IR }(0.72)\end{array}$ & [70] \\
\hline$M: F=1: 1.6$ & 5292 & 77 & $\mathrm{D}_{3}: 800 \mathrm{IU} / \mathrm{d}\left(\mathrm{Ca}^{++} 1000 \mathrm{mg} / \mathrm{d}\right)$ & $2-5$ & HR (0.16) & [71] \\
\hline$M: F=1: 1.3$ & 200 & 48 & $\mathrm{D}_{3}: 3332 \mathrm{IU} / \mathrm{d}$ & 1 & $\begin{array}{l}\mathrm{HbA} 1 \mathrm{c}(0.96) \\
\operatorname{FPG}(0.39)\end{array}$ & [72] \\
\hline$M: F=1: 1$ & 32 & 56 & $D_{3}: 5714 \mathrm{IU} / \mathrm{d}^{6}$ & 0.5 & $\begin{array}{l}\text { FPG }(0.43) \\
\text { HOMA-IR (0.58) }\end{array}$ & [73] \\
\hline$M: F=1: 1.8$ & 438 & 38 & $\begin{array}{l}\mathrm{D}_{3}: 5714 \mathrm{IU} / \mathrm{d}\left(\mathrm{Ca}^{++} 500 \mathrm{mg} / \mathrm{d}\right)^{7} \\
\mathrm{D}_{3}: 2857 \mathrm{IU} / \mathrm{d}\left(\mathrm{Ca}^{++} 500 \mathrm{mg} / \mathrm{d}\right)^{8}\end{array}$ & 1 & NSC & [74] \\
\hline
\end{tabular}

Table I. Summary of the observational longitudinal cohort studies and randomized controlled trials evaluating the effect of vitamin $D$ on diabetes and its related risk factors ${ }^{1}$

${ }^{1}$ Cross-sectional or retrospective case-control studies and randomized trials of a period less than one month were excluded

${ }^{2}$ About half the studied cohort in each trial is placebo. In those studies where there are two treatments, the number of subjects is divided to approximately 3 equal groups to include the placebo treatment

3 "Levels" refers to the serum vitamin D levels as $25(\mathrm{OH}) \mathrm{D}$, whereas "intake" refers to dietary intake

4-6 The treatments are the daily equivalent doses of: ${ }^{4} 120,000 \mathrm{IU} / \mathrm{d} \times 3$ times; ${ }^{5} 100,000 \mathrm{IU} / \mathrm{d}$ given once; and ${ }^{6}$ $40,000 \mathrm{IU} / \mathrm{wk}$

7,8 The treatments represent the daily equivalence to 40,000 and 20,000 IU/wk, respectively

${ }^{9}$ Duration of follow-up for the observational longitudinal cohort studies whereas duration for treatment is for the randomized controlled trials

${ }^{10}$ Significant values are presented in bold text

$\mathrm{d}=$ day; FPG = fasting plasma glucose; HbA1C = glycated hemoglobin; HOMA-IR = homeostasis model of assessment-insulin resistance; $\mathrm{HR}=$ hazard ratio; OGIS = oral glucose insulin sensitivity; NSC = no significant changes; $\mathrm{OR}=$ odds ratio; $\mathrm{RR}=$ relative risk. 
proposition is supported by our recent findings that increasing plasma vitamin D level by $10 \mathrm{nmol} / \mathrm{l}$ was significantly inversely associated with HOMA-IR $(\mathrm{p}=0.006)$ and results in $14 \%$ lower probability of having metabolic syndrome, a major risk factor in T2DM (CI $=0.75-0.99)$ [23]. To our knowledge, there are no long-term studies ( $\geq 6$ months) examining the effects of higher vitamin $\mathrm{D}$ doses ( $\geq 4000$ IU/day) on $2 \mathrm{hr}$ post-challenge glucose, insulin sensitivity and secretion, disposition index, "omics"based inflammatory markers and markers of hepatic steatosis in pre-diabetic subjects with vitamin D deficiency. Therefore, we are currently conducting a long-term clinical trial across Canada to evaluate the efficacy of $2000 \mathrm{IU} / \mathrm{d}$ vitamin D supplementation (for 6 months) on insulin homeostasis and serum glucose levels to evaluate its effect on the risk of T2DM.

\section{Conclusion}

The current state of knowledge warrants further study into the extent of association between inflammatory markers and early stages of T2DM, on the one hand, and the role of vitamin D in modifying this relationship, on the other hand. Such an approach is critical to comprehensively evaluate the possible application of inflammatory network assessment in disease surveillance. The development of such evidence-based biomarkers can be introduced as a public health genomic-based measure for T2DM early prediction, in addition to other traditional risk factors such as family history or physical examination. In this respect, inflammatory biomarkers may permit capturing the etiological function of (and interaction between) genetic constitution and environmental risk modifiers in the T2DM pathogenesis. Furthermore, a major benefit of introducing inflammatory markers into public health settings stems from their potential to facilitate developing a novel class of agents which attenuate low-grade inflammation prior to the clinical onset of T2DM and to be employed in disease prevention. However, before applying these biomarkers in public health, protocols for their assessment should be standardized and laboratory reference intervals need to be applied in decision-making processes.

Employing this set of biomarkers in evaluating responses to prevention may necessitate examining the dynamic interaction between genetic and dietary modifiers in the etiology of T2DM. It seems likely that vitamin D can modify the genotype-phenotype association within the innate immune response. This proposition may elucidate the mechanisms by which vitamin $\mathrm{D}$ and other nutritional factors -which can be introduced into the general population and susceptible subpopulations - prevent or delay disease development. Recently, we demonstrated that vitamin D status can provide an excellent marker of "good" health, including positive associations with young age, normal body weight and a healthy lifestyle $[23,75]$. The potential role of vitamin D supplementation in combating the inflammatory cytokines and improving impaired glycemia and insulin resistance, holds enormous public health implications. Evaluating the efficacy of vitamin D in this prospect may demand a series of pilot clinical studies to be further explored, developed, and optimized, that include developing tools to accurately and reproducibly measure the circulating/tissue levels of potential biomarkers in order to relate them to clinical outcome. The impact of vitamin D on T2DM incidence may then be assessed through a series of pilot population-based studies: firstly, to determine the feasibility and effectiveness of this protocol; second, to validate and evaluate the strategy and ensure replication of results; and, third, to monitor the outcome to quantify the overall preventive response in comparison (and combination) with the current preventive approaches for T2DM such as lifestyle changes, exercise, and dietary intervention.

\section{Author contribution}

All authors contributed to the development of the study concept, preparation of the paper and critically revised the manuscript for intellectual contents, and read and approved the final draft. 


\section{Questions for further research}

What is the utility of inflammatory markers in T2DM early risk prediction and surveillance?

This set of evidence-based biomarkers can be employed as precise phenotypic measures for risk prediction for T2DM beyond the simple risk factors presently employed, such as family history or physical examination, since it is involved both in diseases development and progression. Inflammatory biomarkers may permit to capture the etiological function of (and interaction between) genetic constitution and environmental risk modifiers in the T2DM pathogenesis.

Is there a role of vitamin $\mathrm{D}$ in the prevention of T2DM?

Current evidence certainly indicates that vitamin D deficiency may play a role in T2DM development and progression to its complications. However, to better define the effect of vitamin $\mathrm{D}$ supplementation on disease prevention, a series of high-quality observational studies and randomized controlled trials should be developed to:

- determine the feasibility and effectiveness of vitamin $D$ in disease prevention;

- validate and evaluate this outcome and ensure replication of results; and

- monitor the outcome to quantify the overall preventive response in comparison (and combination) with the current preventive approaches for T2DM such as lifestyle changes, exercise, and dietary interventions.

\section{Acknowledgements}

Research in this manuscript was funded by Public Health Agency of Canada, Canada (AB) and the Supreme Council of Health, Qatar (ES and MHA-T). The authors thank Dr. M. Farid for his suggestions on the manuscript.

\section{The review in brief}

\section{Clinical question This review analyzes the potential beneficial effect of vitamin D on T2DM}

Type of review Narrative

Search of the PubMed with follwing keywords: Inflammation; Prevention; Public health; Type 2 diabetes; Vitamin D literature

Conclusions Research reviewed in the present article concludes that: 1) genetic variants in the innate immunityrelated inflammation initiate a metabolic trait related to metabolic syndrome and T2DM, an observation that provided a rationale for studying their use as biomarkers of disease early risk prediction; 2) attenuation of inflammation (e.g., by vitamin D) can be employed as a novel approach for disease prevention; and 3) high-quality observational studies and randomized controlled trials that measure blood vitamin D levels and disease-related metabolic phenotypes are needed

Limitations Overall, conclusions drawn from research in this article warrant a confirmation for the potential beneficial effect of vitamin D on T2DM. Large trials conducted in well-defined populations (e.g., prediabetes, subjects at disease risk, different ethnic and culture sub-populations) should be specifically designed to test the hypothesis that vitamin D status is a direct contributor to T2DM pathogenesis. Such an intervention, if proven effective, could have substantial public health implications

\section{References}

1. Wild S, Rolic C, Green A. Global prevalence of diabetes: estimates for the year 2000 and projection for 2030. Diabetes Care 2004; 37: 1047-53; http://dx.doi.org/10.2337/diacare.27.5.1047 
2. Cameau P. New diabetes treatment and prevention strategies needed. CMAJ 2007; 176: 1401-2; http://dx.doi.org/10.1503/cmaj.070482

3. Moore AF, Florez JC. Genetic susceptibility to type 2 diabetes and implications for antidiabetic therapy. Annu Rev Med 2008; 59: 95-111; http://dx.doi.org/10.1146/annurev.med.59.090706.135315

4. Swenne I. Pancreatic beta-cell growth and diabetes mellitus. Diabetologia 1992; 35:1 93-201; http:// dx.doi.org/10.1007/BF00400917

5. Butler AE, Janson J, Bonner-Weir S, et al. Beta-cell deficit and increased beta-cell apoptosis in humans with type 2 diabetes. Diabetes 2003; 52: 102-10; http://dx.doi.org/10.2337/diabetes.52.1.102

6. Pickup JC. Inflammation and activated innate immunity in the pathogenesis of type 2 diabetes. Diabetes Care 2004; 27: 813-23; http://dx.doi.org/10.2337/diacare.27.3.813

7. Pickup JC, Matttock MB, Chusney GD, et al. NIDDM as a disease of the innate immune system: association of acute phase reactants and interleukin-6 with metabolic syndrome X. Diabetologia 1997; 40: 1286-92; http://dx.doi.org/10.1007/s001250050822

8. Pickup JC, Crook MA. Is Type II diabetes mellitus a disease of the innate immune system? Diabetologia 1998; 41: 1241-8; http://dx.doi.org/10.1007/s001250051058

9. Houstis N, Rosen ED, Lander ES. Reactive oxygen species have a causal role in multiple forms of insulin resistance. Nature 2006; 440: 944-8; http://dx.doi.org/10.1038/nature04634

10. Hotamisligil GS. Inflammation and metabolic disorders. Nature 2006; 444: 860-7; http://dx.doi. org/10.1038/nature05485

11. Cone JB. Inflammation. Am J Surg 2001; 182: 558-62; http://dx.doi.org/10.1016/S00029610(01)00822-4

12. Medzhitov R, Janeway C. Innate immunity. N Engl J Med 2000; 343: 338-44; http://dx.doi. org/10.1056/NEJM200008033430506

13. Hotamisligil GS, Arner P, Caro JF, et al. Increased adipose tissue expression of tumor necrosis factor-a in human obesity and insulin resistance. J Clin Invest 1995; 95: 2409-15; http://dx.doi. org/10.1172/JCI117936

14. Fernandez-Real JM, Pickup JC. Innate immunity, insulin resistance and type 2 diabetes. TRENDS Endocrin Metabol 2007; 19: 10-6; http://dx.doi.org/10.1016/j.tem.2007.10.004

15. Badawi A, Klip A, Haddad P, et al. Type 2 diabetes mellitus and inflammation: prospects for biomarkers of risk and nutritional intervention. Diabet, Metabol Syndrome Obesity 2010; 3: 173-86; http://dx.doi.org/10.2147/DMSOTT.S9089

16. Garcia-Bailo B, El-Sohemy A, Haddad P, et al. Vitamins D, C and E in the prevention of Type II Diabetes Mellitus: Modulation of inflammation and oxidative stress. Biologics 2010; 5: 7-19

17. Baz-Hecht M, Goldfine AB. The impact of vitamin D deficiency on diabetes and cardiovascular risk. Curr Opin Endocrinol Diabetes Obes 2010; 17: 113-9; http://dx.doi.org/10.1097/ MED.0b013e3283372859

18. $\mathrm{Lu} \mathrm{L}, \mathrm{Wu} \mathrm{Y}, \mathrm{Qi} \mathrm{Q}$, et al. Associations of Type 2 diabetes with common variants in PPARD and the modifying effect of vitamin D among middle-aged and elderly Chinese. PLoS One 2012; 7: e34895; http://dx.doi.org/10.1371/journal.pone.0034895

19. Norman AW. From vitamin D to hormone D: fundamentals of the vitamin D endocrine system essential for good health. Am J Clin Nutr 2008; 88: 491S-499S

20. Shils ME, Shike M, Ross AC, et al. Modern Nutrition in Health and Disease. Baltimore: Lippincott Williams \& Wilkins, 2006

21. Gilchrest BG. Sun exposure and vitamin D sufficiency. Am J Clin Nutr 2008; 88: 570S-577S

22. Gozdzik A, Barta JL, Wu H, et al. Low wintertime vitamin D levels in a sample of healthy young adults of diverse ancestry living in the Toronto area: associations with vitamin $\mathrm{D}$ intake and skin pigmentation. BMC Pub Heal 2008; 8: 336; http://dx.doi.org/10.1186/1471-2458-8-336 
23. Brenner DR, Arora P, Garcia-Bailo B, et al. Plasma vitamin D and risk of the metabolic syndrome in Canadians. Clin Invest Med 2011; 34: E377-E384

24. Fu L, Yun F, Oczak M, et al. Common genetic variants of the vitamin D binding protein (DBP) predict differences in response of serum 25-hydroxyvitamin D [25(OH)D] to vitamin D supplementation. Clin Biochem 2009; 42: 1174-7; http://dx.doi.org/10.1016/j.clinbiochem.2009.03.008

25. Wang TJ, Zhang F, Richards JB, et al. Common genetic determinants of vitamin D insufficiency: a genome-wide association study. Lancet 2010; 376: 180-8; http://dx.doi.org/10.1016/S01406736(10)60588-0

26. Ahn J, Yu K, Stolzenberg-Solomon R, et al. Genome-wide association study of circulating vitamin D levels. Hum Mol Genet 2010; 19: 2739-45; http://dx.doi.org/10.1093/hmg/ddq155

27. Jones G. Pharmacokinetics of vitamin D toxicity. Am J Clin Nutr 2008; 88: 582S-586S

28. Vieth R, Bischoff-Ferrari H, Boucher BJ, et al. The urgent need to recommend an intake of vitamin $\mathrm{D}$ that is effective. Am J Clin Nutr 2007; 85: 649-50

29. Health Canada. Dietary reference intakes - reference values for vitamins. 29-6. Health Canada, 2006

30. Institute of Medicine. Dietary reference intakes for calcium and vitamin D. 2010. 30-11-2010

31. Vieth R. Vitamin D supplementation, 25-hydroxyvitamin D concentrations, and safety. Am J Clin Nutri 1999; 69: 842-56

32. Cannell JJ, Hollis BW. Use of vitamin D in clinical practice. Altern Med Rev 2008; 13:6-2033

33. Langlois K, Greene-Finestone L, Little J, et al. Vitamin D status of Canadians as measured in the 2007 to 2009 Canadian Health Measures Survey. Health Rep 2010; 21: 47-55

34. Harris SS, Dawson-Hughes B. Seasonal changes in plasma 25-hydroxyvitamin D concentrations of young American black and white women. Am J Clin Nutri 1998; 67: 1232-6

35. Maestro B, Dívila N, Carranza MC, et al. Identification of a Vitamin D response element in the human insulin receptor gene promoter. J Steroid Biochem Mol Biol 2003; 84: 223-30; http://dx.doi. org/10.1016/S0960-0760(03)00032-3

36. Bland R, Markovic D, Hills CE, et al. Expression of 25-hydroxyvitamin D3-1-alpha-hydroxylase in pancreatic islets. J Steroid Biochem Mol Biol 2004; 89-90: 121-5; http://dx.doi.org/10.1016/j. jsbmb.2004.03.115

37. Baier LJ, Dobberfuhl AM, Pratley RE, et al. Variations in the vitamin D-binding protein (Gc locus) are associated with oral glucose tolerance in nondiabetic Pima Indians. J Clin Endocrinol Metab 1998; 83: 2993-6; http://dx.doi.org/10.1210/jc.83.8.2993

38. Szathmary EJ. The effect of Gc genotype on fasting insulin level in Dogrib Indians. Hum Genet 1987; 75: 368-72; http://dx.doi.org/10.1007/BF00284110

39. Hirai M, Suzuki S, Hinokio Y, et al. Variations in vitamin D-binding protein (group-specific component protein) are associated with fasting plasma insulin levels in Japanese with normal glucose tolerance. J Clin Endocrinol Metab 2000; 85: 1951-3; http://dx.doi.org/10.1210/jc.85.5.1951

40. Zeitz U, Weber K, Soegiarto DW, et al. Impaired insulin secretory capacity in mice lacking a functional vitamin D receptor. FASEB J 2003; 17: 509-11

41. Sooy K, Schermerhorn T, Noda M, et al. Calbindin-D (28k) controls [Ca2+](i) and insulin release. Evidence obtained from calbindin-D(28k) knockout mice and beta cell lines. J Biol Chem 1999; 274: 34343-9; http://dx.doi.org/10.1074/jbc.274.48.34343

42. Pittas AG, Harris SS, Stark PC, et al. The effects of calcium and vitamin D supplementation on blood glucose and markers of inflammation in nondiabetic adults. Diabetes Care 2007; 30: 980-6; http://dx.doi.org/10.2337/dc06-1994

43. Griffin MD, Xing N, Kumar R. Vitamin D and its analogs as regulators of immune activities and antigen presentation. Annu Rev Nutr 2003; 23: 117-45; http://dx.doi.org/10.1146/annurev. nutr.23.011702.073114 
44. Cantorna MT, Zhu Y, Froicu M, et al. Vitamin D status, 1,25-dihydroxy-vitamin D3, and the immune system. Am J Clin Nutr 2004; 80: 1717S-1720S

45. Riachy R, Vandewalle B, Moerman E, et al. 1,25-dihydroxyvitamin D3 protects human pancreatic islets against cytokine-induced apoptosis via down-regulation of the Fas receptor. Apoptosis 2006; 11: 151-9; http://dx.doi.org/10.1007/s10495-006-3558-z

46. DeLuca HF, Cantorna MT. Vitamin D: its role and uses in immunology. FASEB J 2001; 15: 2579 85; http://dx.doi.org/10.1096/fj.01-0433rev

47. Veldman CM, Cantorna MT, DeLuca HF. Expression of 1,25-dihydroxyvitamin D3 receptor in the immune system. Arch Biochem Biophys 2000; 374: 338; http://dx.doi.org/10.1006/abbi.1999.1605

48. Schleithoff SS, Zittermann A, Tenderich G, et al. Vitamin D supplementation improves cytokine profiles in patients with congestive heart failure: a double-blind, randomized, placebo-controlled trial. Am J Clin Nutr 2006; 83: 754-9

49. Riachy R, Vandewalle B, Kerr CJ, et al. 1,25-dihydroxyvitamin D3 protects RINm5F and human islet cells against cytokine-induced apoptosis: implication of the antiapoptotic protein A20. Endocrinology 2002; 143: 4809-19; http://dx.doi.org/10.1210/en.2002-220449

50. van Etten E, Mathieu C. Immunoregulation by 1,25-dihydroxyvitamin D3: basic concepts. J Steroid Biochem Mol Biol 2005; 97: 93-101; http://dx.doi.org/10.1016/j.jsbmb.2005.06.002

51. Cigolini M, Iagulli MP, Miconi V, et al. Serum 25-hydroxyvitamin D3 concentrations and prevalence of cardiovascular disease among type 2 diabetic patients. Diabetes Care 2006; 29: 722-4; http://dx.doi.org/10.2337/diacare.29.03.06.dc05-2148

52. Isaia G, Giorgino R, Adami S. High prevalence of hypovitaminosis D in female type 2 diabetic population. Diabetes Care 2001; 24: 1496; http://dx.doi.org/10.2337/diacare.24.8.1496

53. Chiu KC, Chu A, Go VL, et al. Hypovitaminosis D is associated with insulin resistance and beta cell dysfunction. Am J Clin Nutr 2004; 79: 820-5

54. Scragg R, Sowers M, Bell C. Serum 25-hydroxyvitamin D, diabetes, and ethnicity in the Third National Health and Nutrition Examination Survey. Diabetes Care 2004; 27: 2813-8; http://dx.doi. org/10.2337/diacare.27.12.2813

55. Liu E, Meigs JB, Pittas AG, et al. Plasma 25-hydroxyvitamin D is associated with markers of the insulin resistant phenotype in nondiabetic adults. J Nutri 2009; 139: 329-34; http://dx.doi. org/10.3945/jn.108.093831

56. Badawi A, Garcia-Bailo B, Arora P, et al. The utility of micronutrients in the prevention of type 2 diabetes and its complications: A public health perspective. In: Oguntibeju O (ed.). Diabetes Mellitus-Book I. InTech Publishing, 2012 [in press]

57. Pittas AG, Dawson-Hughes B, Li T, et al. Vitamin D and calcium intake in relation to type 2 diabetes in women. Diabetes Care 2006; 29: 650-6; http://dx.doi.org/10.2337/diacare.29.03.06.dc051961

58. Arora P, Garcia-Bailo B, Dastani Z, et al. Genetic polymorphisms of innate immunity-related inflammatory pathways in type 2 diabetes mellitus: Biomarkers of early detection and prevention. BMC Med Genet 2010

59. Borissova AM, Tankova T, Kirilov G, et al. The effect of vitamin D3 on insulin secretion and peripheral insulin sensitivity in type 2 diabetic patients. Int J Clin Pract 2003; 57: 258-61

60. de Boer IH, Tinker LF, Connelly S, et al. Calcium plus vitamin D supplementation and the risk of incident diabetes in the Women's Health Initiative. Diabetes Care 2008; 31: 701-7; http://dx.doi. org/10.2337/dc07-1829

61. Gedik O, Akalin S. Effects of vitamin D deficiency and repletion on insulin and glucagon secretion in man. Diabetologia 1986; 29: 142-5; http://dx.doi.org/10.1007/BF02427083

62. von Hurst PR, Stonehouse W, Coad J. Vitamin D supplementation reduces insulin resistance in South Asian women living in New Zealand who are insulin resistant and vitamin D deficient - 
a randomised, placebo-controlled trial. Br J Nutr 2010; 103: 549-55; http://dx.doi.org/10.1017/ S0007114509992017

63. Nagpal J, Pande JN, Bhartia A. A double-blind, randomized, placebo-controlled trial of the short-term effect of vitamin D3 supplementation on insulin sensitivity in apparently healthy, middle-aged, centrally obese men. Diabet Med 2009; 26: 19-27; http://dx.doi.org/10.1111/j.14645491.2008.02636.x

64. Knekt P, Laaksonen M, Mattila C, et al. Serum vitamin D and subsequent occurrence of type 2 diabetes. Epidemiology 2008; 19: 666-71; http://dx.doi.org/10.1097/EDE.0b013e318176b8ad

65. Kirii K, Mizoue T, Iso $\mathrm{H}$, et al. Calcium, vitamin $\mathrm{D}$ and dairy intake in relation to type 2 diabetes risk in a Japanese cohort. Diabetologia 2009; 52: 2542-50; http://dx.doi.org/10.1007/s00125-0091554-x

66. Liu S, Song Y, Ford ES, et al. Dietary calcium, vitamin D, and the prevalence of metabolic syndrome in middle-aged and older US women. Diabetes Care 2005; 28: 2926-32; http://dx.doi.org/10.2337/ diacare.28.12.2926

67. Pittas AG, Sun Q, Manson JE, et al. Plasma 25-hydroxyvitamin D concentration and risk of incident type 2 diabetes in women. Diabetes Care 2010; 33: 2021-3; http://dx.doi.org/10.2337/dc100790

68. Liu E, Meigs JB, Pittas AG, et al. Predicted 25-hydroxyvitamin D score and incident type 2 diabetes in the Framingham Offspring Study. Am J Clin Nutr 2010; 91: 1627-33; http://dx.doi.org/10.3945/ ajcn.2009.28441

69. Nilas L, Christiansen C. Treatment with vitamin D or its analogues does not change body weight or blood glucose level in postmenopausal women. Int J Obes 1984; 8: 407-11

70. Sugden JA, Davies JI, Witham MD, et al. Vitamin D improves endothelial function in patients with Type 2 diabetes mellitus and low vitamin D levels. Diabet Med 2008; 25: 32-5; http://dx.doi. org/10.1111/j.1464-5491.2007.02360.x

71. Avenell A, Cook JA, MacLennan GS, et al. Vitamin D supplementation and type 2 diabetes: a substudy of a randomised placebo-controlled trial in older people (RECORD trial, ISRCTN 51647438). Age Ageing 2009; 38: 606-9; http://dx.doi.org/10.1093/ageing/afp109

72. Zittermann A, Frisch S, Berthold HK, et al. Vitamin D supplementation enhances the beneficial effects of weight loss on cardiovascular disease risk markers. Am J Clin Nutr 2009; 89: 1321-7; http://dx.doi.org/10.3945/ajcn.2008.27004

73. Jorde R, Figenschau Y. Supplementation with cholecalciferol does not improve glycaemic control in diabetic subjects with normal serum 25-hydroxyvitamin D levels. Eur J Nutr 2009; 48: 349-54; http://dx.doi.org/10.1007/s00394-009-0020-3

74. Jorde R, Sneve M, Torjesen P, et al. No improvement in cardiovascular risk factors in overweight and obese subjects after supplementation with vitamin D3 for 1 year. J Intern Med 2010; 267: 46272; http://dx.doi.org/10.1111/j.1365-2796.2009.02181.x

75. DaCosta L, Arora P, Garcia-Bailo B, et al. The association between obesity, cardiometabolic disease biomarkers and innate immunity-related inflammation in Canadian adults. Diabet Metabol Syndrome Obesity 2012; 5 [In press] 